\title{
Vorwort des Herausgebers der 3. Auflage
}

Die vorliegende 3. Auflage der "Qualitativen Schnellanalyse“ konnte wegen des Todes von Herrn Prof. Alwin ScHLEICHER nicht mehr von ihm selbst herausgegeben werden. Doch hatte Herr Prof. SCHLEICHER mich noch vor seinem Tode mit seinen Gedanken hinsichtlich der Neuauflage vertraut gemacht und die Bekanntschaft mit Herrn Prof. Charlot, Paris, vermittelt. - Ich hoffe, das Werk in seinem Sinne fortgesetzt zu haben.

Hinsichtlich der Anionennachweise ist jedoch eine gewisse Änderung eingetreten, da ich es für angebracht hielt, die von CHARLOT herausgebrachte Neufassung in der 3 . Auflage zu berücksichtigen. Im Vorwort zu dieser weist der Verfasser darauf hin, da $B$ vor allem die Reaktionen auf Anionen vervollkommnet wurden und daneben auch die Kationenbestimmung verbessert werden konnte. An der Form und Zielsetzung des Büchleins ist nichts verändert worden. Es bleibt nach wie vor ein handliches Arbeitsbuch für das Laboratorium. 
